\title{
Н.В. Покровская
}

\section{НАЛОГОВЫЕ УСЛОВИЯ ДЛЯ БИЗНЕСА В СТРАНАХ С ФОРМИРУЮЩИМСЯ РЫНКОМ ${ }^{1}$}

\begin{abstract}
В статье рассматриваются налоговые условия ведения бизнеса в странах $c$ различным уровнем финансового развития. Целью исследования является характеристика налоговых особенностей стран с формирующимися финансовыми рынками. По итогам исследования легкости уплаты налогов по странам с развитым, формируюшимся финансовыми рынками и странам-фронтирам было подтверждено наличие особенностей налоговых условий для бизнеса в каждой из групп стран. Для стран с формирующимися финансовыми рынками характерны в среднем более высокие ставки налогов на прибыль, а наибольшую и наиболее различаюшуюся по странам нагрузку на бизнес формируют налоги на труд. В странах с формирующимся рынком также высоки издержки бизнеса, связанные с уплатой налогов и обусловленные большим временем на исполнение налоговых обязательств, большим числом платежей, более затратными процедурами после подачи отчетности и уплаты налогов.

Ключевые слова: налоговые условия бизнеса, легкость уплаты налогов, налог на прибыль, развитый финансовый рынок, формирующийся финансовый рынок, финансовое развитие.
\end{abstract}

Важным аспектом международных финансовых сравнений является уровень финансового развития стран. По этому показателю выделяют развитые и неразвитые финансовые системы; вместе с тем отдельно анализируются формирующиеся финансовые рынки. Профессиональное сообщество обычно рассматривает формирующиеся финансовые рынки как особую группу, занимающую промежуточное положение между развитыми и неразвитыми рынками (см. подробнее [1]). Финансовые институты на формирующихся финансовых рынках имеют свою специфику (см., например, [2-4]), отражающуюся и на налоговой системе [5], а также исполнении налоговых обязательств [6, 7]. Показатели, используемые при оценке финансового развития, различаются. В частности, Всемирный экономический форум анализирует в этих целях банковские финансовые услуги, бизнес-климат, доступность финансовых ресурсов, институциональный климат, небанковские финансовые услуги, финансовую стабильность и финансовые рынки [8]. Направленность на повышение уровня финансового развития стран с формирующимися рынками находит свое отражение в различных аспектах государственной политики. Налогообложение не явля-

\footnotetext{
${ }^{1}$ Исследование выполнено при финансовой поддержке РФФИ в рамках научного проекта № 18-010-00085.
} 
ется самостоятельным фактором для оценки финансового развития, осуществляемой ключевыми международными структурами и институтами. При этом очевидно, что в системе публичных финансов отражается общее состояние финансовых рынков.

Исследования, рассматривающие налоговую политику в странах с формирующимся и неразвитым рынком, позволяют сделать следующие обобщения в части специфики налоговых условий для бизнеса в зависимости от уровня финансового развития:

- необходимость получать достаточные доходы для финансирования основных государственных расходов без использования чрезмерных заимствований обусловливает относительно высокую потребность государства в налоговых поступлениях; при этом важная задача - формирование налоговых доходов таким образом, чтобы максимально соблюдался принцип справедливости, отрицательное воздействие на экономическую деятельность было минимальным, а налоговая система оставалась конкурентоспособной [9];

- низкие доходы населения и теневая экономика не позволяют подоходному налогообложению граждан играть такую же роль, как в развитых странах, что предопределяет высокую значимость косвенных налогов и налогов с бизнеса [10];

- издержки на сбор и администрирование налогов в развитых странах значимо ниже издержек в иных странах. В формирующихся и неразвитых финансовых системах существенны и расходы бизнеса на выполнение налоговых обязательств [11]. При этом первые издержки могут быть снижены, но за счет роста расходов бизнеса, что сохраняет высокое административное давление на бизнес в странах с формирующимся рынком. При этом в макроэкономических исследованиях затратами на уплату налогов со стороны бизнеса зачастую пренебрегают в связи со сложностями их однозначной оценки и учета.

Целью данного исследования является выделение особенностей налоговых условий для бизнеса в странах с формирующимся рынком. На основе предшествующих исследований и предполагаемых целевых установок налоговой политики в странах с формирующимся рынком можно сделать несколько предположений о возможных различиях между налоговыми условиями для бизнеса в странах с формирующимися финансовыми рынками, а также странах с развитыми финансовыми рынками и странахфронтирах. Во-первых, это гипотеза о наличии отличительных черт налоговых условий для корпоративного сектора в странах с формирующимся рынком. Во-вторых, предположение о более низкой налоговой нагрузке на бизнес в рассматриваемых странах. И в-третьих, гипотеза о значимо более обременительных для бизнеса процедурах расчета и уплаты налогов (выражающихся и во временных затратах на исполнение налоговых обязательств, и в количестве платежей, и в сложности процессов после подачи отчетности) в странах с формирующимся рынком. 


\section{Методика исследования}

Показатели оценки налоговых условий ведения бизнеса и их источников вызывают немало дискуссий $[12,13]$, в частности индекс глобальной конкурентоспособности Всемирного экономического форума, индекс экономической свободы. Однако наилучшим образом отражают налоговые условия бизнеса составляющие показателя «легкости уплаты налогов» рейтинга «Ведение бизнеса», формируемого Всемирным банком совместно с компанией PricewaterhausCoopers; данные показатели и стали базой для анализа. В рейтинг легкости ведения бизнеса, помимо налогообложения, входят оценки условий создания предприятий, получения разрешений на строительство, подключения к системе электроснабжения, регистрации собственности, получения кредитов, защиты миноритарных инвесторов, международной торговли, обеспечения исполнения контрактов, разрешения неплатежеспособности [14]. Согласно методологии составления рейтинга легкости уплаты налогов, опубликованной на русском языке на официальном сайте проекта, анализируются налоги и обязательные отчисления, которые предприятие средних размеров должно уплатить в соответствующем году, а также административное бремя, связанное с уплатой налогов и отчислений, и процессы после подачи отчетности и уплаты налогов. В число рассматриваемых налогов и отчислений входят: налог на прибыль или на доходы предприятий; отчисления на социальное обеспечение и налоги на рабочую силу, уплачиваемые работодателем; налоги на собственность; налоги на передачу собственности; налог на дивиденды; налог на прирост капитала; налог на финансовые операции; налоги на сбор отходов; налоги на транспортные средства и дорожные налоги; любые другие налоги или сборы [15]. Для многих стран данный рейтинг является ориентиром развития налоговой системы, а продвижение в рейтинге служит одним из критериев оценки налоговой политики. В частности, с 2008 по 2019 г. материковый Китай продвинулся в рейтинге с 168-го до 114-го места [16, с. 241-242], Россия - со 130-го до 53-го места.

Для целей формирования рейтинга легкости уплаты налогов страны, включенные в анализ (следует отметить, что с 2008 г. число рассматриваемых стран возросло, это повлекло за собой и неизбежные изменения в рэнкинге), сопоставляются по трем (четырем с 2018 г.) блокам показателей: общая налоговая ставка (состоящая из трех значений - ставки налогов на прибыль предприятий, налогов на труд, прочих налогов), время на исполнение налоговых обязательств (также с разделением на время, затрачиваемое для налогов на прибыль предприятий, налогов на труд, налогов на потребление), количество налоговых платежей (в т.ч. по налогам на прибыль предприятий, налогам на труд, прочим налогам). С 2018 г. рейтинг дополнен учетом процессов после подачи отчетности и уплаты налогов в соответствующем индексе, с 2019 г. индекс формализован для межстрановых сравнений по данному показателю.

В ходе исследования рассматривались соответствующие составляющие показателя «легкости уплаты налогов» 2019 г. [17, 18] (рассчитанные по 
данным за 2017 г.) по группам стран с развитым рынком, странамфронтирам и странам с формирующимся финансовым рынком.

В рассматриваемые группы были включены страны, по которым не было противоречий в оценке финансового развития FTSE country classification [19] и S\&P Dow Jones Indices' Annual Country Classification [20, 21]. Таким образом, в анализ были включены данные по 25 странам с развитым финансовым рынком - Австралии, Австрии, Бельгии, Великобритании, Германии, специальному административному району КНР Гонконгу, Дании, Израилю, Ирландии, Испании, Италии, Канаде, Люксембургу, Нидерландам, Новой Зеландии, Норвегии, Португалии, Республике Корея, Сингапуру, США, Финляндии, Франции, Швейцарии, Швеции, Японии; по 22 странам с формирующимся финансовым рынком - Бразилии, Венгрии, Греции, Египту, Индии, Индонезии, Катару, материковому Китаю, Колумбии, Малайзии, Мексике, Объединенным Арабским Эмиратам, Пакистану, Перу, России, провинции КНР Тайваню, Таиланду, Турции, Филиппинам, Чешской Республике, Чили, Южной Африке; по 25 странам с пограничным значением, которые в будущем могут быть включены в страны с формирующимся финансовым рынком (странам-фронтирам), - Аргентине, Бангладеш, Бахрейну, Болгарии, Ботсване, Вьетнаму, Гане, Иордании, Казахстану, Кении, Кипру, Котд’Ивуару, Латвии, Литве, Маврикию, Марокко, Нигерии, Оману, Румынии, Словакии, Словении, Тунису, Хорватии, Шри-Ланке, Эстонии.

Для наглядности экспресс-сравнения по каждому из четырех групп показателей было рассчитано среднее значение для стран группы, дисперсия для характеристики размаха вариации значений и коэффициента вариации для сравнения различий между значениями по группам, а также было проанализировано распределение значений по группам показателей.

\section{Результаты сравнения налоговых условий для бизнеса в странах с формирующимся рынком, с развитым рынком и в странах-фронтирах}

В рейтинг легкости уплаты налогов 2019 г. были включены 189 стран. Из 72 стран, вошедших в исследование, 60\%, в т.ч. Российская Федерация, входит в первую треть стран с наибольшей легкостью уплаты налогов, больше половины из которых (23 страны) имеют развитый финансовый рынок. Развитый финансовый рынок признают, в частности, для специального административного района КНР Гонконга, занимающего 1-е место в рейтинге легкости уплаты налогов, Ирландии (5-е место рейтинга), Сингапура, Дании и Новой Зеландии ( 8,9 и 10-е места рейтинга соответственно). Однако страны, которые делят 2-е место рейтинга (Катар и Объединенные Арабские Эмираты), имеют формирующийся финансовый рынок; 5-е место рейтинга легкости уплаты налогов Бахрейна и 6-е место Маврикия сочетается с пограничным состоянием развитости финансового рынка. В треть стран с наименьшей легкостью уплаты налогов вошло 11 стран, включенных в исследование, их них 36\% (4 страны) имеют формирую- 
щийся финансовый рынок, а 64\% (7 стран) - пограничное значение; наихудшие значения легкости уплаты налогов среди стран с развитым финансовым рынком делят Италия и Япония (97-е место рейтинга).

В табл. 1 представлены средние значения и дисперсия налоговых ставок, времени на исполнение налоговых обязательств, количества налоговых платежей и характеристики процессов после подачи отчетности и уплаты налогов по странам с развитым рынком, формирующимся рынком и странам-фронтирам.

\section{Таблица 1. Характеристика легкости уплаты налогов в зависимости от уровня финансового развития}

\begin{tabular}{|c|c|c|c|c|c|c|}
\hline & \multicolumn{2}{|c|}{$\begin{array}{c}\text { Страны с развитым } \\
\text { финансовым рынком }\end{array}$} & \multicolumn{2}{|c|}{$\begin{array}{c}\text { Страны с формиру- } \\
\text { ющимся финансовым } \\
\text { рынком }\end{array}$} & \multicolumn{2}{|c|}{ Страны-фронтиры } \\
\hline & \begin{tabular}{|c|} 
Среднее \\
значение \\
\end{tabular} & Дисперсия & $\begin{array}{c}\text { Среднее } \\
\text { значение }\end{array}$ & Дисперсия & $\begin{array}{l}\text { Среднее } \\
\text { значение }\end{array}$ & Дисперсия \\
\hline $\begin{array}{l}\text { 1. Общая налоговая } \\
\text { ставка, в \%, в т.ч.: }\end{array}$ & 37,7 & 145,6 & 42 & 210,9 & 38,5 & 334,5 \\
\hline $\begin{array}{l}\text { ставка налогов } \\
\text { на прибыль }\end{array}$ & 15,7 & 65,1 & 16,7 & 68,7 & 12,2 & 72,4 \\
\hline $\begin{array}{l}\text { ставка налогов } \\
\text { на труд }\end{array}$ & 19,8 & 153,0 & 20,9 & 159,9 & 18,9 & 115 \\
\hline $\begin{array}{l}\text { ставка прочих } \\
\text { налогов }\end{array}$ & 2,1 & 5,5 & 6,6 & 82,1 & 7,4 & 258,5 \\
\hline $\begin{array}{l}\text { 2. Время на испол- } \\
\text { нение налоговых } \\
\text { обязательств в } \\
\text { часах, в т.ч.: }\end{array}$ & 128,0 & 2902,5 & 213,5 & 6585,4 & 199,3 & 14704 \\
\hline $\begin{array}{l}\text { по налогам } \\
\text { на прибыль }\end{array}$ & 38,6 & 585,4 & 60,3 & 1589,3 & 45,6 & 1255,7 \\
\hline $\begin{array}{l}\text { по налогам } \\
\text { на труд }\end{array}$ & 52,9 & 832,4 & 71 & 1652,4 & 76,8 & 2865,9 \\
\hline $\begin{array}{l}\text { по налогам на } \\
\text { потребление }\end{array}$ & 36,4 & 390,2 & 87 & 2595,6 & 76,9 & 2791,8 \\
\hline $\begin{array}{l}\text { 3. Количество } \\
\text { налоговых плате- } \\
\text { жей, шт., в т.ч.: }\end{array}$ & 12,0 & 59,6 & 14,2 & 143,0 & 20,1 & 221,6 \\
\hline $\begin{array}{l}\text { по налогам } \\
\text { на прибыль }\end{array}$ & 1,6 & 1,0 & 2 & 7,2 & 2,1 & 3,2 \\
\hline $\begin{array}{l}\text { по налогам } \\
\text { на труд }\end{array}$ & 3,8 & 18,9 & 5 & 39,8 & 6,7 & 59,9 \\
\hline $\begin{array}{l}\text { по прочим } \\
\text { налогам }\end{array}$ & 6,6 & 10,2 & 7,3 & 19,8 & 11,3 & 85,1 \\
\hline $\begin{array}{l}\text { 4. Индекс процес- } \\
\text { сов после подачи } \\
\text { отчетности и упла- } \\
\text { ты налогов }\end{array}$ & 85,8 & 136,1 & 55,0 & 439,1 & 67,4 & 533,6 \\
\hline
\end{tabular}

Примечание. Данные по странам с формирующимся финансовым рынком представлены без сведений по Бразилии, которые существенно искажают средние значения.

Источник: составлено автором. 
Ключевым параметром, по которому характеризуют налоговые условия бизнеса, являются ставки соответствующих налогов; распределение стран по уровню ставок налогов представлено в табл. 2. Совокупная налоговая ставка в большинстве стран с формирующимся рынком составляет от 40 до 60\%, а в странах с развитым финансовым рынком - от 20 до 40\%; средняя налоговая ставка также выше в странах с формирующимся финансовым рынком, что опровергает наши предположения, сделанные перед началом исследования. Однако не следует делать вывод и о том, что со снижением уровня финансового развития снижаются налоговые ставки. Хотя среднее значение данного показателя в странах-фронтирах ближе к странам с развитым рынком, распределение значений существенно различается от минимальных значений 13,8\% в Бахрейне до 60,2\% в Тунисе и даже $106 \%$ в Аргентине.

Таблица 2. Распределение стран по уровню налоговых ставок в зависимости от уровня финансового развития

\begin{tabular}{c|c|c|c|c|c}
\hline Значение ставок, \% & $\begin{array}{c}\text { От 0 до } \\
20 \%\end{array}$ & $\begin{array}{c}\text { От 20 } \\
\text { до 40\% }\end{array}$ & $\begin{array}{c}\text { От 40 } \\
\text { до 60\% }\end{array}$ & $\begin{array}{c}\text { От 60 } \\
\text { до 80\% }\end{array}$ & $\begin{array}{c}\text { Свыше } \\
100 \%\end{array}$ \\
\hline
\end{tabular}

Страны с развитым финансовым рынком

\begin{tabular}{l|c|c|c|c|c}
\hline Общая налоговая ставка & & 56 & 40 & 4 & \\
\hline Ставка налогов на прибыль & 68 & 32 & & & \\
\hline Ставка налогов на труд & 64 & 28 & 8 & & \\
\hline Ставка прочих налогов & 100 & & & & \\
\hline
\end{tabular}

Страны с формирующимся финансовым рынком

\begin{tabular}{l|c|c|c|c|c}
\hline Общая налоговая ставка & 9 & 32 & 45 & 14 & \\
\hline Ставка налогов на прибыль & 45 & 55 & & & \\
\hline Ставка налогов на труд & 55 & 41 & 5 & & \\
\hline Ставка прочих налогов & 90 & 10 & & & \\
\hline
\end{tabular}

Ставка прочих налогов -

\begin{tabular}{l|c|c|c|c|c}
\hline Общая налоговая ставка & 4 & 64 & 24 & 4 & 4 \\
\hline Ставка налогов на прибыль & 78 & 22 & & & \\
\hline Ставка налогов на труд & 52 & 48 & & & \\
\hline Ставка прочих налогов & 87 & 9 & & 4 & \\
\hline
\end{tabular}

Источник: составлено автором.

Для стран-фронтиров характерны: более низкие ставки налогов на прибыль, более существенные различия (как внутри группы, так и по сравнению с другими группами стран) в ставках налогов, отличных от налогов на прибыль и налогов на труд (особенно показателен случай Бразилии, где ставка прочих налогов составила $72,8 \%$, что меньше совокупной налоговой ставки во всех остальных странах, включенных в анализ); наибольшая частота отсутствия отдельных видов налогов (в частности, нулевая ставка характерна для прибыли в Бахрейне и Хорватии, трудовых ресурсов в Бангладеш и Ботсване, по прочим налогам в Гане и Омане). Хотя нулевая ставка применяется и в странах с формирующимся финансовым рынком (в Катаре - для прибыли и прочих налогов, в ОАЭ - для прибыли), но все же в среднем составляющие системы налогообложения бизнеса формирую- 
щихся стран весьма похожи (или стремятся быть похожими) на соответствующие системы развитых стран. Во всех анализируемых странах налог на труд формирует основную налоговую нагрузку на бизнес, однако наибольшие различия в налоговых ставках в странах с формирующимся рынком характерны для налогов на труд, а в странах-фронтирах - для прочих налогов. Общая налоговая ставка в России $(46,3 \%)$ превышает среднее значение по группе стран, притом что ставки налогов на прибыль и прочих налогов значимо ниже. Основную тяжесть обложения в Российской Федерации формируют налоги на труд - 36,4\% в соответствии с методологией составления рейтинга. Налогообложение российского бизнеса остается конкурентоспособным с налоговыми условиями стран-экономических партнеров, в частности Китая [22].

Относительно числа налоговых платежей наблюдается прямая связь чем ниже уровень финансового развития, тем больше число налоговых платежей и тем больше различия между странами. Притом что общее количество платежей не превосходит 10 для большей половины стран и с развитым, и с формирующимся рынком (табл. 3), для последних характерно существенно большее число стран с существенно большим числом платежей (например, 47 платежей в Пакистане и 43 платежа в Индонезии)

\section{Таблица 3. Распределение стран по количеству налоговых платежей в зависимости от уровня финансового развития}

\begin{tabular}{|c|c|c|c|c|c|}
\hline Количество платежей & Ровно 1 & \begin{tabular}{|c|} 
От 2 до \\
10
\end{tabular} & $\begin{array}{l}\text { От } 10 \\
\text { до } 20 \\
\end{array}$ & $\begin{array}{l}\text { От } 20 \\
\text { до } 30 \\
\end{array}$ & $\begin{array}{c}\text { Свыше } \\
30\end{array}$ \\
\hline \multicolumn{6}{|c|}{ Страны с развитымм финансовым рынком } \\
\hline Количество налоговых платежей & & $60 \%$ & $24 \%$ & $16 \%$ & \\
\hline $\begin{array}{l}\text { Количество платежей по налогам на при- } \\
\text { быль }\end{array}$ & $64 \%$ & $36 \%$ & & & \\
\hline Количество платежей по налогам на труд & $44 \%$ & $40 \%$ & $16 \%$ & & \\
\hline Количество платежей по прочим налогам & $4 \%$ & $84 \%$ & $12 \%$ & & \\
\hline \multicolumn{6}{|c|}{ Страны с формирующчимся финансовым рынком } \\
\hline Количество налоговых платежей & & $59 \%$ & $23 \%$ & $9 \%$ & $9 \%$ \\
\hline Количество платежей по налогам на прибыль & $64 \%$ & $32 \%$ & $5 \%$ & & \\
\hline Количество платежей по налогам на труд & $32 \%$ & $50 \%$ & $14 \%$ & $5 \%$ & \\
\hline Количество платежей по прочим налогам & & $86 \%$ & $14 \%$ & & \\
\hline \multicolumn{6}{|c|}{ Cтраньы-фронтирьы } \\
\hline Количество налоговых платежей & & $44 \%$ & $16 \%$ & $12 \%$ & $28 \%$ \\
\hline Количество платежей по налогам на прибыль & $60 \%$ & $40 \%$ & & & \\
\hline Количество платежей по налогам на труд & $52 \%$ & $8 \%$ & $32 \%$ & $8 \%$ & \\
\hline Количество платежей по прочим налогам & $4 \%$ & $56 \%$ & $28 \%$ & $4 \%$ & $8 \%$ \\
\hline
\end{tabular}

Источник: составлено автором.

Наименьшие отличия между группами характерны для числа платежей по налогам на прибыль - в более чем в 60\% стран каждой из групп по данным налогам осуществляется один платеж. Однако наибольшее число платежей по налогам на прибыль (13 шт.) взимается в Индонезии, стране с формирующимся рынком. Хотя наибольшее число стран с одним платежом по 
налогам на труд входит в группу стран с пограничным значением развития финансового рынка, в этой же группе больше стран со значительным числом платежей; это характерно еще в большей степени для числа платежей по прочим налогам. Число налоговых платежей в Российской Федерации (1 платеж по налогам на прибыль, 2 платежа по налогам на труд и 4 платежа по прочим налогам) соответствует лучшей практике развитых стран.

Число платежей само по себе характеризует административные издержки бизнеса на предоставление налоговой отчетности, однако наиболее наглядным показателем данных издержек является количество часов на соблюдение налогового законодательства. Любопытно, что хотя в среднем для стран-фронтиров характерно большее число налоговых платежей, наибольшее время на исполнение налоговых обязательств требуется в странах с формирующимся финансовым рынком.

Если в 80\% стран с развитым финансовым рынком на исполнение налоговых обязательств бизнесом затрачивается менее 150 часов (табл. 4), то в $80 \%$ стран с формирующимся финансовым рынком - более 150 часов. При этом именно для группы стран с формирующимся рынком характерны наиболее трудоемкие процедуры соблюдения налогового законодательства (1 958 часов в Бразилии, 392 часа в Египте, 296 часов в Чили, 294 часа в Пакистане и т.д.).

Таблица 4. Распределение стран по уровню налоговых ставок в зависимости от уровня финансового развития

\begin{tabular}{|c|c|c|c|c|}
\hline Время, ч & До $50 \%$ & $\begin{array}{c}\text { От } 50 \\
\text { до } \\
100 \%\end{array}$ & $\begin{array}{c}\text { От } 100 \\
\text { до } \\
150 \%\end{array}$ & $\begin{array}{c}\text { Свыше } \\
150 \%\end{array}$ \\
\hline \multicolumn{5}{|c|}{ Страны с развитым финансовым рынком } \\
\hline Время на исполнение налоговых обязательств & 4 & 24 & 52 & 20 \\
\hline $\begin{array}{l}\text { Время на исполнение обязательств по налогам на } \\
\text { прибыль }\end{array}$ & 84 & 12 & 4 & \\
\hline Время на исполнение обязательств по налогам на труд & 52 & 44 & 4 & \\
\hline $\begin{array}{l}\text { Время на исполнение обязательств по налогам на } \\
\text { потребление }\end{array}$ & 88 & 12 & & \\
\hline \multicolumn{5}{|c|}{ Страны с формируюшимся финансовым рынком } \\
\hline Время на исполнение налоговых обязательств & 9 & & 5 & 86 \\
\hline $\begin{array}{l}\text { Время на исполнение обязательств по налогам на } \\
\text { прибыль }\end{array}$ & 50 & 32 & 9 & 9 \\
\hline Время на исполнение обязательств по налогам на труд & 41 & 36 & 14 & 9 \\
\hline $\begin{array}{l}\text { Время на исполнение обязательств по налогам на } \\
\text { потребление }\end{array}$ & 23 & 36 & 23 & 18 \\
\hline \multicolumn{5}{|l|}{ Страны-фрронтиры } \\
\hline Время на исполнение налоговых обязательств & 8 & 8 & 20 & 64 \\
\hline $\begin{array}{l}\text { Время на исполнение обязательств по налогам на } \\
\text { прибыль }\end{array}$ & 64 & 28 & 8 & \\
\hline Время на исполнение обязательств по налогам на труд & 36 & 44 & 12 & 8 \\
\hline $\begin{array}{l}\text { Время на исполнение обязательств по налогам на } \\
\text { потребление }\end{array}$ & 28 & 48 & 12 & 12 \\
\hline
\end{tabular}

Источник: составлено автором. 
Наибольшее время на исполнение обязательств по налогам на прибыль тратит бизнес в странах с формирующимися финансовыми рынками: в Бразилии (462 часа) и на Тайване (161 час), по налогам на труд - в Бразилии (335 часов) и Египте (165 часов), по налогам на потребление - в Бразилии (1161 час) и Пакистане (214 часов). Однако существенны данные значения и в странах-фронтирах, тем более что, как было показано выше, общее число налогов в этих странах выше, что обусловливает и административную нагрузку. Общее число часов на исполнение налоговых обязательств в Российской Федерации (остающееся на протяжении последних лет на уровне 168 часов, несмотря на активное внедрение различных сервисов и инструментов, облегчающих уплату налогов) ниже соответствующего значения в $82 \%$, или 18 стран с формирующимся рынком, и $20 \%$ стран с развитым финансовым рынком.

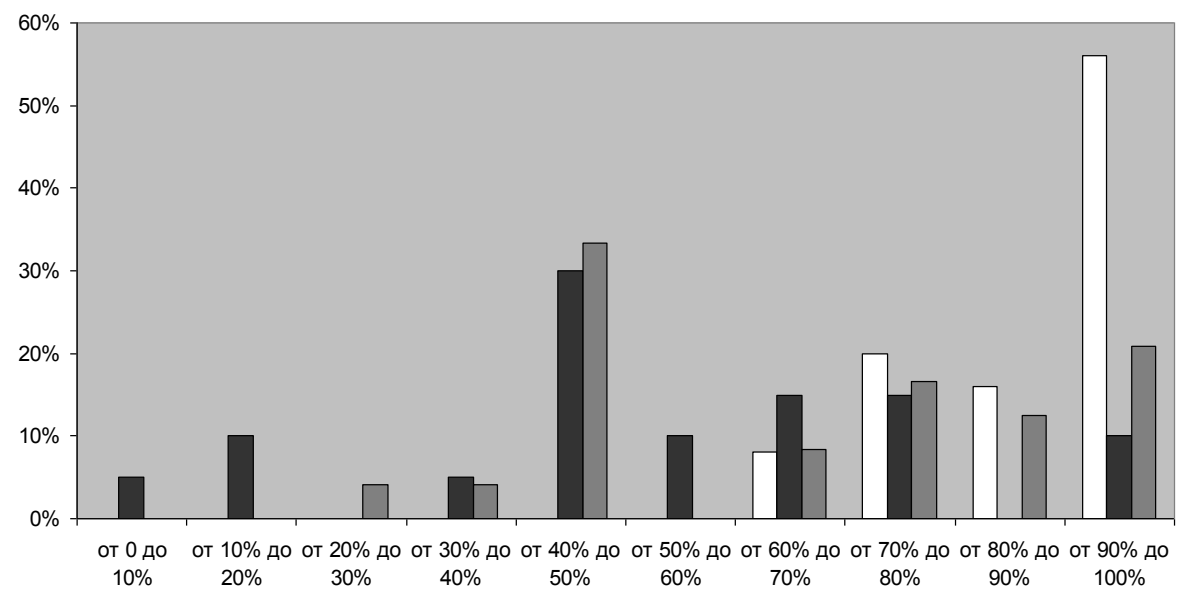

$\square$ Страны с развитым финансовым рынком $\square$ Страны с формирующимся финансовым рынком $\square$ Страны-фронтиры

Рис. 1. Распределение стран по индексу процедур после подачи отчетности и уплаты налогов в зависимости от уровня финансового развития

Рейтинг легкости уплаты налогов 2019 г. позволяет сравнить еще один аспект издержек бизнеса на уплату налогов - процедуры после подачи отчетности и уплаты налогов. В соответствии с официальной методологией данный индекс основан на четырех компонентах: времени на соблюдение требований для возврата НДС, времени на получение возврата НДС, времени на соблюдение требований корректировки по налогу на прибыль и времени для корректировки налога на прибыль [23]. Если в стране применимы оба вида налогов - НДС и налог на прибыль, то индекс процедур после подачи отчетности и уплаты налогов рассчитывается как среднее арифметическое баллов по каждому из четырех компонентов. Если же в стране применяется только один вид налогов - НДС либо налог на прибыль, то индекс процедур после подачи отчетности и уплаты налогов рас- 
считывается как среднее арифметическое баллов только по двум компонентам, относящимся к соответствующему налогу. Если не применяется ни НДС, ни налог на прибыль, то индекс не включается в рейтинг легкости уплаты налогов [15]. Среди анализируемых стран индекс не рассчитывался по Бахрейну, Катару и ОАЭ. Индекс рассчитывается в процентах, при этом наиболее удобные для бизнеса процедуры после подачи отчетности и уплаты налогов равны 1, наименее удобные - 0. Данный индекс не поддается прямой трактовке, но позволяет осуществлять межстрановые сравнения.

Значение индекса процедур после подачи отчетности и уплаты налогов свыше 90\% (рис. 1) наблюдается в 14 странах с развитым финансовым рынком, 5 странах-фронтирах (Латвия, Литва, Эстония, Маврикий, Марокко) и лишь в 2 странах с формирующимся финансовым рынком (Тайвань и Чехия).

Именно для стран с формирующимся финансовым рынком характерны и наименьшие значения индекса $(7,8 \%$ в Бразилии, $10,5 \%$ в Пакистане, $19,2 \%$ в Перу), это обусловливает и наименьшие средние значения показателя (55\%). Среднее значение для стран-фронтиров несколько выше $(67,4 \%)$, однако и различия между странами группы тоже существенно выше. Значение данного показателя для Российской Федерации 73,6\% является достаточно высоким для стран с формирующимся рынком, но все же в большинстве стран с развитым финансовым рынком процедуры после подачи отчетности и уплаты налогов признаются существенно более удобными для бизнеса.

\section{Выводы}

По итогам проведенного исследования первая гипотеза о наличии особенностей налоговых условий для бизнеса в странах с формирующимся рынком в целом подтвердилась. Притом что формально средние ставки значимо между группами, по данным на 2017 г., не различались, время на исполнение налоговых обязательств, количество платежей по налогам на труд и показатели легкости уплаты налогов в контексте процессов после подачи отчетности и уплаты налогов существенно варьировались между группами; при этом наибольшие отличия были именно в налогах на труд.

Вторая гипотеза не нашла своего обоснования: однозначного вывода о более низкой налоговой нагрузке, выражаемой в ставке налога на среднее предприятие в странах с формирующимся рынком, по представленным данным сделать нельзя. Для стран-фронтиров характерны более низкие ставки налогов на прибыль и налогов на труд, но более высокие ставки прочих налогов. Вообще система обязательных платежей бизнеса в странах-фронтирах более отличается от налоговых систем стран с развитым и формирующимся финансовыми рынками. При этом в странах с формирующимся рынком большую и более различающуюся по странам нагрузку формируют налоги на прибыль и труд. 
Третья гипотеза нашла полное подтверждение. Издержки бизнеса на соблюдение налогового обязательства выше в странах с формирующимся рынком по сравнению со странами с развитым рынком и относительно времени на исполнение налоговых обязательств, и относительно числа платежей, и по процедурам после подачи отчетности и уплаты налогов. Среднее значение показателя времени на исполнение налоговых обязательств по группе стран с формирующимся рынком почти в 2 раза превышает это значение по группе стран с развитым рынком. Любопытно, что наименьшие различия между группами в этом наборе показателей наблюдаются для числа платежей по налогу на прибыль. Вероятно, этот показатель легче всего гармонизировать между странами.

Индекс процессов после подачи отчетности и уплаты налогов является новой составляющей индекса легкости уплаты налогов и публикуется с 2017 г. Он весьма удобен для дополнения характеристик институциональных условий налогообложения, так как характеризует прежде всего затраты (в том числе временные) на возврат НДС и на проверку по налогу на прибыль корпораций. Пожалуй, именно этот показатель наиболее наглядно демонстрирует различия между налоговыми системами стран с развитым и формирующимся финансовыми рынками.

Таким образом, можно выделить следующие особенности налоговых условий для бизнеса в странах с формирующимся рынком: большие затраты времени на исполнение обязанностей по уплате налогов, а также на возмещение НДС и налоговые проверки; большее число уплачиваемых налоговых платежей; большее значение ставки налогов на труд.

Отмеченные особенности стран с формирующимся финансовым рынком наглядно проявляются при анализе данных по России. Общая налоговая ставка на российский бизнес выше, чем в среднем по странам с формирующимся рынком, а ставка налога на прибыль - ниже. Административные издержки уплаты налогов в России в настоящее время ближе к показателям стран с развитым рынком, чем стран с формирующимся рынком. Это явилось результатом планомерной государственной политики по улучшению условий для исполнения налоговых обязательств, при этом целевыми показателями было именно улучшение позиции страны на анализируемом рынке, что было успешно достигнуто. Количество налоговых платежей бизнеса в России ниже среднего показателя по странам с формирующимся рынком. Однако индекс процессов после подачи отчетности и уплаты налогов России все же значимо отличается от индекса стран с развитым финансовым рынком. Таким образом, можно отметить меньшие административные издержки и все же более высокую тяжесть налогов, уплачиваемых бизнесом в России.

Интерес для дальнейших исследований может иметь анализ тенденций развития налоговых систем (предполагаем более существенные изменения в налоговых системах в странах с формирующимся рынком и большую стабильность налоговых систем стран с развитым рынком и странфронтиров), расширение анализируемых показателей и включение в них 
условий налогообложения крупного бизнеса, значимости налогов корпоративного сектора относительно ВВП, а также отраслевых особенностей [24], оказывающих влияние на налоговые условия ведения бизнеса в странах с формирующимся финансовым рынком.

\section{Литература}

1. Львова Н.А. Концепция сравнительной оценки финансовых систем // Актуальные проблемы экономики. 2016. № 5. С. 308-316.

2. Воронова Н.С., Мирошниченко О.С., Тарасова А.Н. Детерминанты развития российского банковского сектора как факторы экономического роста // Экономические и социальные перемены: факты, тенденции, прогноз. 2016. № 4 (46). С. 165-183.

3. Кормишкина Л.А., Королева Л.П. Зарубежный опыт фискального стимулирования развития возобновляемой энергетики // Финансы и кредит. 2018. Т. 24, № 8 (776). C. $1891-1905$.

4. Иванов В.В., Бушуева Н.В. Внешние источники финансирования российских предприятий: реалии и перспективы // Вестник Санкт-Петербургского университета. Экономика. 2007. № 1. С. 96-107.

5. Покровская Н.В. Влияние кризиса на налоговые условия заемного финансирования российских компаний // Экономика и экологический менеджмент. 2015. № 4. С. 70-76.

6. Теневая экономика и уклонение от уплаты налогов: монография / под ред. А.П. Киреенко, Д.Ю. Федотова. Иркутск : ИрГУПС, 2017. 202 с.

7. Львова Н.А., Покровская Н.В., Воронова Н.С. Концепция финансовых парадоксов: предпосылки становления и траектории развития // ЭКО. 2017. № 6. С. 164-177.

8. Reuttner I., Glass T. The Financial Development Report. Geneva, NY : World Economic Forum, 2012.

9. Tanzi V., Zee H. Tax policy for emerging markets: developing countries // National Tax Journal. 2000. Vol. 53, № 2. P. 299-322.

10. Amaglobeli D., Crispolti V., Dabla-Norris E., Karnane P., Misch F. Tax policy measures in advanced and emerging economies: a novel database. IMF Working Paper, 2018.

11. Bird R., Zolt. E. Tax policy in emerging countries // Environment and Planning C: Government and Policy. 2008. Vol. 26. P. 73-86.

12. Иванов В.В. Методологические аспекты оценки налоговой дисциплины // Экономика. Налоги. Право. 2014. № 3. С. 89-92.

13. Вылкова E.C. Налоговая составляющая показателей эффективности деятельности хозяйствующих субъектов // Известия Иркутской государственной экономической академии. 2012. № 4 (84). С. 39-43.

14. Doing Business 2019. Training for Reform. 16th Edition. The World Bank, International Bank for Reconstruction and Development, 2019. 311 p. URL: http://www.worldbank.org/content/dam/doingBusiness/media/Annual-Reports/English/DB2019-report_webversion.pdf (access date: 08.02.2019).

15. Методология составления рейтинга «Налогообложение». URL: http://russian.doingbusiness.org/ru/methodology/paying-taxes (дата обращения: 08.02.2019).

16. Финансовая система Китая / под ред. В.В. Иванова. М., 2018. 352 с.

17. Paying Taxes 2018. PWC, World Bank Group, 2018. 46 p.

18. Paying Taxes. Data explorer. PWC. URL: https://www.pwc.com/gx/en/services/ tax/publications/paying-taxes-2019.html (access date: 08.02.2019).

19. FTSE Annual Country Classification Review. Published: 26 September 2018. URL: https://www.ftse.com/products/downloads/FTSE-Country-Classification-Update_latest.pdf (access date: 08.02.2019).

20. $S \& P$ Dow Jones Indices' Annual Country Classification Consultation. Published: June, 2017. URL: https://us.spindices.com/documents/index-news-and-announcements/ 20170615-spdji-annual-country-classification-consultation.pdf (access date: 08.02.2019). 
21. $S \& P$ Dow Jones Indices' 2018 Country Classification Consultation Results. Published: December, 2018. URL: https://www.spice-indices.com/idpfiles/spice-assets/resources/ public/documents/828959_spdji2018countryclassificationconsultationre-sults12.5.2018.pdf (access date: 08.02.2019).

22. Синенко О.А., Цыганова Т.Д. Участие России в проекте «Экономического пояса нового шелкового пути»: возможности и перспективы // Вестник Морского государственного университета. 2017. № 77 (77). С. 71-76.

23. Djankov S., Ganser T., McLiesh C., Ramalho R., Shleifer A. The Effect of Corporate Taxes on Investment and Entrepreneurship // American Economic Journal: Macroeconomics. 2010. Vol. 2 (3). P. 31-64.

24. Баландина А.C. Подходы к дифференциации налогообложения нефтегазового сектора экономики // Вестник Томского государственного университета. Экономика. 2012. № 3 (19). C. 44-47.

\section{Tax Conditions for Business in Emerging Market Countries}

Vestnik Tomskogo gosudarstvennogo universiteta. Ekonomika - Tomsk State University Journal of Economics. 2019. 46. pp. 215-228.

DOI: $10.17223 / 19988648 / 46 / 15$

Natalya V. Pokrovskaia, Saint Petersburg State University (Saint Petersburg, Russian Federation). E-mail: n.pokrovskaia@spbu.ru

Keywords: tax conditions for business, ease of paying taxes, income tax, developed financial market, emerging financial market, financial development.

The article addresses the tax conditions for doing business in countries with different levels of financial development. The aim of the study is to characterize the business tax conditions of countries with emerging financial markets. According to the results of the study of the ease of paying taxes for countries with developed, emerging financial markets and for frontier countries, it has been confirmed that there are particular tax conditions for businesses in each group of countries. For countries with emerging financial markets, on average, higher rates of income taxes are typical, and labor taxes are the largest and most differing burden on business. In emerging market countries, business costs associated with paying taxes are also high due to the long time to comply, a large number of payments, more costly procedures after filing reports and paying taxes.

\section{References}

1. L'vova, N.A. (2016) The concept of financial systems' comparative evaluation. Aktual'nye problemy ekonomiki - Actual Problems of Economics. 5. pp. 308-316. (In Russian).

2. Voronova, N.S., Miroshnichenko, O.S., Tarasova, A.N. (2016) Determinants of the Russian Banking Sector Development as the Drivers of Economic Growth. Ekonomicheskie $i$ sotsial'nye peremeny: fakty, tendentsii, prognoz - Economic and Social Changes: Facts, Trends, Forecast. 4 (46). pp. 165-183. (In Russian). DOI: 10.15838/esc.2016.4.46.9

3. Kormishkina, L.A. \& Koroleva, L.P. (2018) Fiscal encouragement of renewable energy development: International practices. Finansy $i$ kredit - Finance and Credit. 2018. 24:8 (776). pp. 1891-1905. (In Russian).

4. Ivanov, V.V. \& Bushueva, N.V. (2007) External Sources of Financing Russian Enterprises: Realities and Perspectives. Vestnik Sankt-Peterburgskogo universiteta. Ekonomika - St. Petersburg University Journal of Economic Studies. 1. pp. 96-107. (In Russian).

5. Pokrovskaya, N.V. (2015) Impact of crisis for tax conditions in Russian companies' debt financing. Ekonomika i ekologicheskiy menedzhment - Economics and Environmental Management. 4. pp. 70-76. (In Russian). 
6. Kireenko, A.P. \& Fedotov, D.Yu. (eds) (2017) Tenevaya ekonomika i uklonenie ot uplaty nalogov [Shadow economy and tax evasion]. Irkutsk: Irkutsk State Transport University.

7. L'vova, N.A., Pokrovskaya, N.V. \& Voronova, N.S. (2017) Kontseptsiya finansovykh paradoksov: predposylki stanovleniya i traektorii razvitiya [The concept of financial paradoxes: prerequisites for the formation and development trajectory]. EKO-ECO. 6 . pp. 164-177. DOI: 10.30680/ECO0131-7652-2017-6-164-177

8. Reuttner, I. \& Glass, T. (2012) The Financial Development Report. Geneva, NY: World Economic Forum.

9. Tanzi, V. \& Zee, H. (2000) Tax policy for emerging markets: developing countries. National Tax Journal. 53 (2). pp. 299-322.

10. Amaglobeli, D. et al. (2018) Tax policy measures in advanced and emerging economies: a novel database. IMF Working Paper.

11. Bird, R. \& Zolt, E. (2008) Tax policy in emerging countries. Environment and Planning C: Government and Policy. 26. pp. 73-86.

12. Ivanov, V.V. (2014) Metodologicheskie aspekty otsenki nalogovoy distsipliny [Methodological aspects of assessing tax discipline]. Ekonomika. Nalogi. Pravo-Economics, Taxes \& Law. 3. pp. 89-92.

13. Vylkova, E.S. (2012) Tax component of business entities' performance indicators. Izvestiya Irkutskoy gosudarstvennoy ekonomicheskoy akademii - Izvestiya of Irkutsk State Economics Academy. 4 (84). pp. 39-43. (In Russian).

14. The World Bank. (2019) Doing Business 2019. Training for Reform. 16th ed. The World Bank, International Bank for Reconstruction and Development. [Online] Available from: http://www.world-bank.org/content/dam/doingBusiness/media/Annual-Reports/English/ DB2019-report_web-version.pdf. (Accessed: 08.02.2019).

15. Russian.doingbusiness.org. (n.d.) Metodologiya sostavleniya reytinga "Nalogooblozhenie" [The methodology for compiling the rating "Taxation"]. [Online] Available from: http://russian.doingbusiness.org/ru/methodology/paying-taxes. (Accessed: 08.02.2019).

16. Ivanov, V.V. \& Pokrovskaya, N.V. (eds) (2018) Finansovaya sistema Kitaya [The financial system of China]. Moscow: Prospekt.

17. PWC \& World Bank Group. (2018) Paying Taxes 2018. PWC, World Bank Group.

18. PWC. (2019) Paying Taxes. Data explorer. [Online] Available from: https://www.pwc.com/ gx/en/services/tax/publications/paying-taxes-2019.html. (Accessed: 08.02.2019).

19. FTSE. (2018) Annual Country Classification Review. [Online] Available from: https:/www.ftse.com/products/downloads/FTSE-Country-Classification-Update_latest.pdf. (Accessed: 08.02.2019).

20. S\&P Dow Jones Indices. (2017) Annual Country Classification Consultation. [Online] Available from: https://us.spindices.com/documents/index-news-and-announcements/20170615spdji-annual-country-classification-consultation.pdf. (Accessed: 08.02.2019).

21. S\&P Dow Jones Indices. (2018) Country Classification Consultation Results. [Online] Available from: https:/www.spice-indices.com/idpfiles/spice-assets/resources/public/ documents828959_spdji2018countryclassificationconsultationre-sults12.5.2018.pdf. (Accessed: 08.02.2019).

22. Sinenko, O.A. \& Tsyganova, T.D. (2017) Opportunities and prospects of Russia's participation in the project of the "Silk Road Economic Belt". Vestnik Morskogo gosudarstvennogo universiteta. 77 (77). pp. 71-76. (In Russian).

23. Djankov, S. et al. (2010) The Effect of Corporate Taxes on Investment and Entrepreneurship. American Economic Journal: Macroeconomics. 2 (3). pp. 31-64.

24. Balandina, A.S. (2012) Podkhody k differentsiatsii nalogooblozheniya neftegazovogo sektora ekonomiki [Approaches to the differentiation of taxation of the oil and gas sector of the economy]. Vestnik Tomskogo gosudarstvennogo universiteta. Ekonomika - Tomsk State University Journal of Economics. (19). pp. 44-47. 